\title{
Vertical structure and strategic environmental trade policy
}

\author{
Stephen F. Hamilton ${ }^{\mathrm{a}}$ and Till Requate ${ }^{\mathrm{b}}$ \\ ${ }^{a}$ Department of Economics, University of Central Florida, Orlando, FL 32816-1400, USA \\ ${ }^{\mathrm{b}}$ Department of Economics, University of Kiel, Olshausen Strasse 40, 24098 Kiel, Germany
}

\begin{abstract}
The idea that environmental trade policy can be used to achieve competitive advantage in international markets has important implications for the way we conceive free trade. This paper considers strategic environmental policy in a model that makes explicit the vertical structure that supports production of the traded good. Including intranational vertical relationships in the analysis of strategic environmental trade policy has substantial qualitative effects. When vertical contracts are allowed, the optimal policy to levy on a polluting input under both quantity and price competition in the international market is the Pigouvian tax.
\end{abstract}

Keywords: Strategic trade; Vertical separation; Environmental policy

\section{Introduction}

The potential use of environmental regulations to achieve competitive advantage in international markets is a topic of growing policy concern. As the WTO continues to tighten restrictions on traditional government export programs, environmental regulations and other input market controls are being increasingly scrutinized as potential instruments for strategic trade. The OECD, the WTO, the European Commission, and other international organizations have recently evaluated possible environmental tax reforms and their effect on national and regional welfare and competitiveness (see $[12,14])$. The possibility that governments may compromise environmental regulations to gain competitive advantage is an issue of considerable policy importance for the way we conceive free trade. 
Since Markusen [11], the potential role of environmental policy as an indirect instrument of trade policy is a subject that has received a great deal of attention. Recent research along these lines has developed international oligopoly models that combine incentives for pollution control with the rent-shifting motivations for trade policy first noted by Brander and Spencer [3]. The balance struck between these opposing incentives has led the strategic environmental trade policy literature to a series of negative results. Under quantity competition in the international oligopoly market, Conrad [5] and Barrett [1] demonstrate that the optimal non-cooperative environmental tax under-internalizes the domestic externality. Under price competition, Barrett [1] derives the opposite result that the optimal non-cooperative environmental policy over-internalizes the domestic externality. ${ }^{1}$ In each case, the incentive of the government regulator to fully internalize domestic environmental damages is tempered, on the margin, by her desire to achieve competitive advantage. This outcome, which has been coined the "environment-for-trade" policy result, has been subsequently extended by Kennedy [10] to examine transboundary pollution, by Nannerup [13] to consider incomplete information, and by Ulph [18], Ulph [17], and Simpson and Bradford [16] to analyze the effect of additional stages of investment and R\&D. These extensions modify, but do not remove, the incentive of the domestic regulator to compromise environmental policy for the interest of trade.

This paper challenges the environment-for-trade policy result by taking a broader view of the vertical industry structure that encompasses the input market. We consider an international environmental policy game that is essentially identical to that in $[1,5]$; however, we introduce within this game an intranational subgame in which downstream and upstream firm(s) engage in vertical contracts of the form considered by Vickers [19] and Bonanno and Vickers [2]. Our analysis thus bridges some major themes in the strategic environmental trade policy and vertical separation literatures: Regulators design environmental policy to balance incentives for pollution control and competitive advantage, while firms employ vertical contracts that respond to this policy design.

We model the case in which environmental regulation is levied on a polluting input while trade occurs in an intermediate or final downstream good. This context, which encompasses many important circumstances of international environmental regulations, allows the potential for decentralized contracts to emerge as a commitment device between vertically separated firms. Bonanno and Vickers [2] consider two-part tariff contracts in vertically separated industries and show that the optimal contract specifies an upstream price below (above) marginal cost when downstream competition involves strategic substitutes (complements). To the extent that this contracted upstream price deviates from the Walrasian price, the vertical contract is a commitment mechanism that plays a similar role as an input subsidy (tax) under strategic trade policy. The essential difference is that participation by the (polluting) upstream firm is voluntary; indeed it must be induced by the payment of a lump-sum tariff in the case of the vertical contract.

The relationship we consider between vertical market structure and international environmental policy is important for several reasons. First, from a trade policy perspective, internationally exchanged goods are often produced in vertically structured sectors that admit the potential for

\footnotetext{
${ }^{1}$ These findings parallel the strategic trade results of Eaton and Grossman [6], who show, in a model without pollution, that the trade policy which maximizes competitive advantage is a subsidy when firms choose strategic substitutes, but a tax when firms choose strategic complements.
} 
contractual linkages to arise between firms. Coordinated vertical relationships are known to exist, moreover, for many important traded goods. Japanese keiretsu and Korean chaebols organizations involve linked equity interests between vertically aligned firms, and in US agricultural markets, "backwards" vertical contracts between food manufacturers and farm product producers are widely recognized as a common practice. ${ }^{2}$ Governments also coordinate vertical markets through the use of state trading enterprises, which create separation between domestic and international markets through payment arrangements that combine an initial transfer price with a share of the subsequent international proceeds. ${ }^{3}$ Second, from an environmental policy perspective, a multi-market framework adds an important dimension to the regulatory context. The primary interface between the economy and the environment is in upstream raw product industries, whereas the balance of international trade is in intermediate and final goods. Finally, from purely a modeling standpoint, suppressing the vertical sequence of production that supports a traded good creates a policy context in which rent-shifting strategies are external to market participants. By construction, this can significantly alter the qualitative implications of the model. In light of these observations, it is surprising to note that there has been virtually no discussion to date on the effect of vertical market structure on the design of international environmental policy.

Under circumstances in which firms engage in vertical contracts, we find the unilateral optimal emission policy to be a Pigouvian tax. This result, which holds under both price and quantity competition in the international market, obtains because a vertical contract provides the exporting firm with an input pricing mechanism that substitutes perfectly for a government subsidy (tax) as a commitment device. Strategic distortion in environmental policy, as a consequence, becomes unnecessary.

The remainder of the paper is organized as follows. In Section 2, we formulate a model consisting of an international environmental policy game between governments and an intranational contract subgame between upstream and downstream firms. In Section 3, we examine the implication of vertical contracts for the non-cooperative policy equilibrium under quantity competition, and in Section 4, we extend the analysis to the case of price competition.

\section{Model structure}

We frame our model around a decentralized vertical market structure that supports a traded good. Productive activities in the sector are organized between an upstream firm and a downstream firm in each country. Upstream firms are competitive and produce a polluting input $(x)$. The polluting input is used by a downstream firm to produce a finished good $(y)$, which is subsequently sold in an international export market. Downstream firms compete, either in quantities or in prices, in a differentiated product market comprised of a domestic firm and a foreign firm, which we denote hereafter with the superscripts $d$ and $f$, respectively.

\footnotetext{
${ }^{2}$ Vertical contracts are also common in the production and distribution of coal and natural gas, in automobile and aerospace industries, and in bulk shipping markets.

${ }^{3}$ Hamilton and Stiegert [9] find that the initial procurement price set by the Canadian Wheat Board generally falls within a range consistent with the optimal contract price to achieve vertical separation in the international durum market.
} 
The timing of the environmental policy game is as follows. In the first stage, the regulator in county $i$ chooses an emission tax rate $\left(t^{i}\right)$ on the polluting input, and in the second stage, the downstream firms compete in an international oligopoly market. The second stage encompasses an intranational contract subgame in which downstream firms can enter into contractual arrangements with upstream suppliers that stipulate rules for exchange of the polluting input.

We consider a two-part tariff, or fixed price, contract form. Fixed price contracts, which are a commonly observed form of contractual arrangement in industrial nations, have been studied extensively in the vertical separation literature (see, e.g., $[4,19]$ under circumstances of quantity competition; [2,15] under price competition). ${ }^{4}$ The terms of the contract written by the downstream firm in country $i$ specify a wholesale price for the polluting input, $\varpi^{i}$, and a fixed transfer payment, $F^{i}$, to be exchanged between the downstream and upstream firms. ${ }^{5}$ Throughout, we place no restrictions on the sign of this fixed transfer.

In the event that the contract is rejected, the downstream firm in country $i$ is assumed to purchase the input on country $i$ 's spot market at a price of $w^{i}=w^{i}\left(t^{i}\right)$. The market price for the polluting input in country $i$, in turn, is governed by the level of the environmental tax in country $i$, $t^{i}$, according to

$$
w^{i}\left(t^{i}\right)=w_{0}^{i}+t^{i} e^{i}
$$

where $w_{0}^{i}$ is the base price of the polluting input and $e^{i}$ is the emissions coefficient in country $i$ (i.e., the quantity of emissions per unit of input). Throughout, we assume that environmental damage is local, and that governments of consuming countries have no means to influence the policy of producing countries.

\section{Quantity competition}

Let $P^{\mathrm{d}}(Y)$ denote the inverse demand function of the domestic firm and $P^{\mathrm{f}}(Y)$ denote the inverse demand function of the foreign firm in the downstream international market, where $Y=\left(y^{\mathrm{d}}, y^{\mathrm{f}}\right)$ is the vector of export quantities, and let $C^{i}\left(y^{i}, w^{i}\left(t^{i}\right)\right)$ denote the variable cost function of downstream firm $i$, where $w^{i}\left(t^{i}\right)$ is the market price of the polluting input given by (1). ${ }^{6}$ Denoting derivatives by subscripts, we assume $C_{y}^{i}>0, C_{y y}^{i} \geqslant 0, C_{w}^{i}>0$, and $C_{y w}^{i}>0$, and limit our attention to circumstances in which the two outputs are substitutes, $P_{j}^{i}<0$.

In the output stage, given that the upstream firm accepts the contract proposed by the domestic downstream firm, the downstream firm maximizes profit, $\pi^{\mathrm{d}}\left(y^{\mathrm{d}}, Y, \varpi^{\mathrm{d}}, F^{\mathrm{d}}\right)=P^{\mathrm{d}}(Y) y^{\mathrm{d}}-$ $C^{\mathrm{d}}\left(y^{\mathrm{d}}, \varpi^{\mathrm{d}}\right)-F^{\mathrm{d}}$, where $\varpi^{\mathrm{d}}$ and $F^{\mathrm{d}}$ are the terms specified previously in the contract. ${ }^{7}$ The

\footnotetext{
${ }^{4}$ The qualitative predictions of the model would be unchanged if the contractual arrangement provided for equitysharing between upstream and downstream firms (see, e.g. [8]).

${ }^{5}$ Depending on the nature of competition, the contract may contain additional clauses such as capacity constraints and exclusive dealing arrangements. See footnotes 8 and 11 .

${ }^{6}$ For notational simplicity, all other input prices in the cost function are suppressed.

${ }^{7}$ Sunk costs, which play no role in the analysis, are consequently omitted.
} 
first-order necessary condition is

$$
\pi_{\mathrm{d}}^{\mathrm{d}}=P^{\mathrm{d}}(Y)+y^{\mathrm{d}} P_{\mathrm{d}}^{\mathrm{d}}(Y)-C_{y}^{\mathrm{d}}\left(y^{\mathrm{d}}, \varpi^{\mathrm{d}}\right)=0 .
$$

Proceeding similarly, the first-order condition for the downstream foreign firm is

$$
\pi_{\mathrm{f}}^{\mathrm{f}}=P^{\mathrm{f}}(Y)+y^{\mathrm{f}} P_{\mathrm{f}}^{\mathrm{f}}(Y)-C_{\mathrm{y}}^{\mathrm{f}}\left(y^{\mathrm{f}}, \varpi^{\mathrm{f}}\right)=0 .
$$

In the event that the downstream firm in country $i$ does not contract with the upstream firm(s), which may occur, for instance, through compliance with antitrust laws in country $i$, then $\varpi^{i}=$ $w^{i}\left(t^{i}\right)$ and $F^{i}=0$ in either (2) or (3).

Letting $\Delta=\pi_{\mathrm{dd}}^{\mathrm{d}} \pi_{\mathrm{ff}}^{\mathrm{f}}-\pi_{\mathrm{df}}^{\mathrm{d}} \pi_{\mathrm{fd}}^{\mathrm{f}}$, we assume the following conditions hold:

$$
\pi_{i i}^{i}<0, \quad \pi_{i j}^{i}<0, \quad \Delta>0 .
$$

The first condition is necessary for profit maximization. The second condition states that a firm's marginal profit decreases with its rival's quantity, which ensures that reaction functions slope downward. The last condition is necessary for stability of the Nash equilibrium. These assumptions imply the existence of a unique equilibrium in quantities defined by the solution to (2) and (3). Denote these equilibrium quantities

$$
Y^{\mathrm{c}}=\left(y^{\mathrm{d}, \mathrm{c}}\left(\varpi^{\mathrm{d}}, \varpi^{\mathrm{f}}\right), y^{\mathrm{f}, \mathrm{c}}\left(\varpi^{\mathrm{d}}, \varpi^{\mathrm{f}}\right)\right) .
$$

Now consider the contract stage of the subgame. To obtain the polluting input, the downstream firm must offer the upstream producer a contract that is (at least weakly) profit increasing. At the same time, the downstream firm will not offer a contract that earns negative profit. It follows that the supplier chosen by the downstream firm in the equilibrium contractual relation agrees to the terms $\left(\varpi^{\mathrm{d}}, F^{\mathrm{d}}\right)$ that maximize the downstream firm's profit subject to a constraint of nonnegative profit in the upstream market,

$$
\max _{\varpi^{\mathrm{d}}, F^{\mathrm{d}}} P^{\mathrm{d}}\left(Y^{\mathrm{c}}\right) y^{\mathrm{d}, \mathrm{c}}-C^{\mathrm{d}}\left(y^{\mathrm{d}, \mathrm{c}}, \varpi^{\mathrm{d}}\right)-F^{\mathrm{d}}
$$

such that

$$
\left(\varpi^{\mathrm{d}}-w^{\mathrm{d}}\left(t^{\mathrm{d}}\right)\right) x^{\mathrm{d}}+F^{\mathrm{d}} \geqslant 0,
$$

where $x^{\mathrm{d}}=x^{\mathrm{d}}\left(y^{\mathrm{d}, \mathrm{c}}\right)$ denotes the quantity of the polluting input, with $x_{y}^{\mathrm{d}}>0 .{ }^{8}$ Recognizing that the optimal contract terms for the domestic downstream firm leave the upstream supplier at the reservation profit level, it follows that (6) always binds. Substituting this expression into (5) yields

$$
\max _{\varpi^{\mathrm{d}}} P^{\mathrm{d}}\left(Y^{\mathrm{c}}\right) y^{\mathrm{d}, \mathrm{c}}-C^{\mathrm{d}}\left(y^{\mathrm{d}, \mathrm{c}}, \varpi^{\mathrm{d}}\right)+\left(\varpi^{\mathrm{d}}-w^{\mathrm{d}}\left(t^{\mathrm{d}}\right)\right) x^{\mathrm{d}} .
$$

\footnotetext{
${ }^{8}$ To ensure non-negative profits for the upstream firm, a contract that specifies $\varpi^{\mathrm{d}}<w^{\mathrm{d}}\left(t^{\mathrm{d}}\right)$ may also involve a capacity constraint that slightly exceeds the equilibrium demand of the downstream firm. In this case, the downstream firm's cost function would exhibit a discontinuity which, although not relevant on the equilibrium path, serves to safeguard the upstream firm off the equilibrium path.
} 
Differentiating (7) with respect to $\varpi^{\mathrm{d}}$ and making use of Shephard's lemma (i.e., $\left.C_{\varpi}^{\mathrm{d}}\left(y^{\mathrm{d}}, \varpi^{\mathrm{d}}\right)=x^{\mathrm{d}}\right)$ gives

$$
\left[P^{\mathrm{d}}+y^{\mathrm{d}, \mathrm{c}} P_{\mathrm{d}}^{\mathrm{d}}-C_{y}^{\mathrm{d}}+\left(\varpi^{\mathrm{d}}-w^{\mathrm{d}}\left(t^{\mathrm{d}}\right)\right) x_{y}^{\mathrm{d}}\right] \frac{\partial y^{\mathrm{d}, \mathrm{c}}}{\partial \varpi^{\mathrm{d}}}+y^{\mathrm{d}, \mathrm{c}} P_{\mathrm{f}}^{\mathrm{d}} \frac{\partial y^{\mathrm{f}, \mathrm{c}}}{\partial \varpi^{\mathrm{d}}}=0 .
$$

Next, substitute (2) into (8) to get

$$
\left(\varpi^{\mathrm{d}}-w^{\mathrm{d}}\left(t^{\mathrm{d}}\right)\right) x_{y}^{\mathrm{d}} \frac{\partial y^{\mathrm{d}, \mathrm{c}}}{\partial \varpi^{\mathrm{d}}}+y^{\mathrm{d}, \mathrm{c}} P_{\mathrm{f}}^{\mathrm{d}} \frac{\partial y^{\mathrm{f}, \mathrm{c}}}{\partial \varpi^{\mathrm{d}}}=0 .
$$

If the foreign downstream firm also adopts a contract, the terms of the profit-maximizing contract for the foreign firm would be symmetric to those implied by (9).

Totally differentiating the first-order conditions from the output stage gives

$$
\frac{\partial y^{\mathrm{d}, \mathrm{c}}}{\partial \varpi^{\mathrm{d}}}=\frac{C_{y \varpi}^{\mathrm{d}} \pi_{\mathrm{ff}}^{\mathrm{f}}}{\Delta}<0, \quad \frac{\partial y^{\mathrm{f}, \mathrm{c}}}{\partial \varpi^{\mathrm{d}}}=\frac{-C_{y \varpi}^{\mathrm{d}} \pi_{\mathrm{fd}}^{\mathrm{f}}}{\Delta}>0 .
$$

Notice that the implicit structure of (9) and (10) ensures that the qualitative nature of the contract by the domestic downstream firm is independent of the foreign firm's choice of contract terms. The rival wholesale price, $\varpi^{\mathrm{f}}$, is an argument that affects only the magnitude, and not the sign, of the comparative statics effects in (10).

Proposition 1. The equilibrium vertical contract for the downstream firm in country $i$ involves an upstream price below the regulated price of the polluting input $\left(\varpi^{i}<w^{i}\left(t^{i}\right)\right)$ and a positive lump sum payment to the upstream firm $\left(F^{i}>0\right)$.

Proof. Suppose not. Then there are two cases to consider for the domestic country. If $\varpi^{\mathrm{d}}=$ $w^{\mathrm{d}}\left(t^{\mathrm{d}}\right)$, then the first term in (9) is zero, while the second term is negative. Therefore $\varpi^{\mathrm{d}} \neq w^{\mathrm{d}}\left(t^{\mathrm{d}}\right)$. If $\varpi^{\mathrm{d}}>w^{\mathrm{d}}\left(t^{\mathrm{d}}\right)$, then both terms are negative. Therefore, $\varpi^{\mathrm{d}}<w^{\mathrm{d}}\left(t^{\mathrm{d}}\right)$, from which $F^{\mathrm{d}}>0$ follows immediately from (6). The same holds for the foreign firm.

By committing to pay a lower input price, the domestic downstream firm is able to increase his oligopoly rent in the international market. In total, of course, the direct contribution of the lower input price to the domestic firm's profit is exactly offset by the payment of a lump-sum transfer to the upstream producer. Nonetheless, a lower input price alters the set of credible actions for the domestic firm in his rivalry with the foreign firm for the international oligopoly rent. By contracting with the upstream producer for a lower input price in exchange for a compensatory fixed payment, the reaction function of the domestic firm shifts to the right, which permits a credible output expansion to take place in the international market.

In stage one of the environmental policy game, the domestic and foreign governments select emission taxes to maximize their respective net benefits. Let the profit of the downstream firm in country $i$ from the contract subgame be denoted by

$$
\tilde{\pi}^{i}\left(t^{\mathrm{d}}, t^{\mathrm{f}}\right)=\max _{y^{i}, \varpi^{i}, F^{i}} \pi^{i}\left(y^{i}, Y, \varpi^{i}, F^{i}\right) .
$$

The domestic welfare standard is the conventional one employed in the strategic environmental trade policy literature in which the output of downstream firm $i$ is not consumed within country $i$ 
and the environmental damage in country $i$ depends only on the emissions in country $i .{ }^{9}$ The objective function of the domestic regulator is

$$
W^{i}\left(t^{\mathrm{d}}, t^{\mathrm{f}}\right)=\tilde{\pi}^{i}\left(t^{\mathrm{d}}, t^{\mathrm{f}}\right)+t^{i} e^{i} x^{i}-D^{i}\left(e^{i} x^{i}\right) .
$$

Maximization of (11) supports the following result.

Proposition 2. If firms in country $i$ employ vertical contracts, the optimal non-cooperative environmental policy under quantity competition is the Pigouvian tax $\left(t^{i}=D_{x}^{i}\right)$.

Proof. Consider the problem of the domestic regulator. Making use of Shepard's lemma, eq. (1), and the downstream firm's profit-maximizing condition (2), the first-order condition for the domestic regulator is

$$
\left(\varpi^{\mathrm{d}}-w_{0}^{\mathrm{d}}\right) x_{y}^{\mathrm{d}} \frac{\partial y^{\mathrm{d}}}{\partial t^{\mathrm{d}}}+y^{\mathrm{d}} P_{\mathrm{f}}^{\mathrm{d}} \frac{\partial y^{\mathrm{f}}}{\partial t^{\mathrm{d}}}-D_{x}^{\mathrm{d}} e^{\mathrm{d}} x_{y}^{\mathrm{d}} \frac{\partial y^{\mathrm{d}}}{\partial t^{\mathrm{d}}}=0 .
$$

Next, divide (12) through by $\frac{\partial y^{\mathrm{d}, \mathrm{c}}}{\partial \mathrm{t}^{\mathrm{d}}}$ and note that the linearity of $t^{\mathrm{d}}$ in (1) implies

$$
\frac{\partial y^{\mathrm{f}}\left(t^{\mathrm{d}}, t^{\mathrm{f}}\right) / \partial t^{\mathrm{d}}}{\partial y^{\mathrm{d}}\left(t^{\mathrm{d}}, t^{\mathrm{f}}\right) / \partial t^{\mathrm{d}}}=\frac{\partial y^{\mathrm{f}, \mathrm{c}}\left(\varpi^{\mathrm{d}}, \varpi^{\mathrm{f}}\right) / \partial \varpi^{\mathrm{d}}}{\partial y^{\mathrm{d}, \mathrm{c}}\left(\varpi^{\mathrm{d}}, \varpi^{\mathrm{f}}\right) / \partial \varpi^{\mathrm{d}}} .
$$

Substitution from (9) results in

$$
\left(t^{\mathrm{d}}-D_{x}^{\mathrm{d}}\right) e^{\mathrm{d}} x_{y}^{\mathrm{d}}=0 .
$$

Noting that $e^{\mathrm{d}}>0$ and $x_{y}^{\mathrm{d}}>0$ implies $t^{\mathrm{d}}=D_{x}^{\mathrm{d}}$. By symmetry, $t^{\mathrm{f}}=D_{x}^{\mathrm{f}}$.

In [1,5], the optimal environmental policy under quantity competition imposes a weaker standard than the Pigouvian level. The reason for this is that under-internalizing marginal damage provides firms with the implicit export subsidy necessary to capture rent in the international market. That is, the optimal non-cooperative policy in these models represents a compromise between the opposing incentives of a government regulator to control pollution, on the one hand, and to provide competitive advantage for her firms on the other. When production is organized through vertical contracts, however, this outcome does not obtain.

The proposition directs attention to an important feature that is implicit in the strategic trade literature. The presumption maintained in this literature is that the domestic regulator is capable of capturing international oligopoly rent that firms cannot themselves acquire through their activities in the private market. When vertical markets are introduced in the analysis, a downstream firm is able to commit to an input price that shifts international rent through decentralized contract design. Government export subsidization, as a consequence, becomes unnecessary.

Models of strategic environmental policy with a private commitment stage have been considered previously by Ulph [18] for the case of emission-reducing R\&D and by Ulph [17] and Simpson and Bradford [16] for the case of cost-reducing R\&D. Apart from Ulph [18], who identifies conditions in which a regulator would over-internalize marginal damage, the finding in

\footnotetext{
${ }^{9}$ Extension of the model in either direction would be relatively straightforward.
} 
this literature is the conventional one that policy under-internalizes the domestic externality. Unlike the case of vertical contracts, private commitment through R\&D investment does not eliminate the role for strategic environmental trade policy. This is because R\&D investment introduces an additional distortion in the model that prevents private and social incentives from aligning as they do here. For example, in [17] the strategic instrument of the regulator is an output tax, which substitutes imperfectly for private instruments levied at the R\&D stage.

It is important to note that vertically structured markets do not necessarily eliminate the role for strategic environmental trade policy. Our model implicitly assumes that vertical contracts are allowed under prevailing antitrust laws, and this produces a bargaining situation between upstream and downstream firms that fully capitalizes the strategic rents associated with input pricing. If vertical contracts are not allowed under prevailing antitrust laws, however, then the conventional strategic environmental trade policy result emerges once more. With vertical markets, a relevant focus for analysis is the relationship between domestic environmental policy and national (and international) antitrust laws.

\section{Price competition}

In this section we sketch the effects of vertical contracts under circumstances in which downstream firms compete in prices rather than in quantities. Let $D^{i}\left(P^{\mathrm{d}}, P^{\mathrm{f}}\right)$ denote the demand function facing firm $i$ in the international market, where $P^{\mathrm{d}}, P^{\mathrm{f}}$ are the prices set by the domestic and foreign firm, respectively. We assume that the products are substitutes and satisfy the definiteness property $D_{i}^{i}<0, \quad D_{j}^{i}>0, \quad D_{i}^{i} D_{j}^{j}-D_{j}^{i} D_{i}^{j} \geqslant 0, \quad$ and $\quad \pi_{i i}^{i}<0, \quad \pi_{i j}^{i}>0, \quad \Omega=\pi_{\mathrm{dd}}^{\mathrm{d}} \pi_{\mathrm{ff}}^{\mathrm{f}}-$ $\pi_{\mathrm{d}}^{\mathrm{d}} \pi_{\mathrm{fd}}^{\mathrm{f}}>D_{j}^{i} \pi_{j i}^{j}$. The latter conditions mirror those under quantity competition and ensure profit maximization, upward-sloping reaction functions, and uniqueness of the Nash equilibrium in prices (see [7]). Finally, we assume $D_{i}^{i} \pi_{j j}^{j}>D_{j}^{i} \pi_{j i}^{j}$, which is a relatively mild condition satisfied whenever the own-price effects on $D^{i}$ and $\pi_{i}^{i}$ are greater than the cross-price effects. Proceeding as in the last section, we arrive at ${ }^{10}$

Proposition 3. The equilibrium vertical contract for the downstream firm in country $i$ involves an upstream price above the regulated price of the polluting input $\left(\varpi^{i}>w^{i}\left(t^{i}\right)\right)$ and a negative lump sum payment to the upstream firm $\left(F^{i}<0\right)$.

The optimal contract under price competition takes essentially the form of the contract considered by Bonanno and Vickers [2] and Shaffer [15]; the downstream firm contracts with the upstream firm to receive a lump-sum transfer in exchange for paying a higher unit price for the input. ${ }^{11}$ This is optimal because a contractual commitment to pay a higher input price by firm $i$

\footnotetext{
${ }^{10}$ Proofs of all propositions are available from the authors upon request.

${ }^{11}$ In contrast to the case of quantity competition, an upstream capacity constraint is not necessary here to protect the interest of upstream firms. However, downstream firms may have an incentive to buy silently from other upstream firms (at competitive prices) in this case. Hence, the contract under price competition may also involve an exclusive dealing provision.
} 
increases downstream production costs, which signals his rival that output will not be priced aggressively in the international market (i.e., a "puppy dog" ploy). The direct effect of the domestic price increase, of course, is exactly compensated by the fixed payment; however, by committing to pay $\varpi^{\mathrm{d}}>w^{\mathrm{d}}\left(t^{\mathrm{d}}\right)$ for the input, the domestic downstream firm provides the foreign downstream firm with an incentive to raise his own price in response. The foreign price increase has a positive first-order effect on domestic profit.

The objective function of the domestic regulator is, as before,

$$
W^{i}\left(t^{\mathrm{d}}, t^{\mathrm{f}}\right)=\hat{\pi}^{i}\left(t^{\mathrm{d}}, t^{\mathrm{f}}\right)+t^{i} e^{i} x^{i}-D^{i}\left(e^{i} x^{i}\right),
$$

where $\hat{\pi}^{i}\left(t^{\mathrm{d}}, t^{\mathrm{f}}\right)=\max _{\left\{P^{i}, \varpi^{i}, F^{i}\right\}} \pi^{i}\left(P^{i}, P, \varpi^{i}, F^{i}\right)$ denotes the profit of the downstream firm in country $i$ in the contract subgame. Maximization of (13) supports

Proposition 4. If firms in country $i$ employ vertical contracts, the optimal non-cooperative environmental policy under price competition is the Pigouvian tax $\left(t^{i}=D_{x}^{i}\right)$.

To the extent that vertical contracts are allowed under prevailing antitrust laws, there is no strategic role for environmental policy. Under either price or quantity competition in the international oligopoly market, the optimal environmental policy is the Pigouvian tax.

\section{Concluding remarks}

This paper considered a noncooperative environmental policy game between governments under circumstances in which a domestic downstream exporter is able to form contractual arrangements with upstream input suppliers. Our results provide sharp contrast with the conventional strategic environmental trade policy result that the optimal tax is set below (above) the Pigouvian level under quantity (price) competition. To the extent that vertical contracts are feasible, we found a deviation from the Pigouvian tax in either case to be suboptimal. The reason for this is that, apart from the pollution externality, the incentive of the domestic regulator is aligned with her firms in the interest of shifting rent. Because the input pricing mechanism offered by a vertical contract is isomorphic to a pollution tax as a commitment instrument, government export promotion becomes unnecessary.

A practical implication of this result is that the optimal non-cooperative environmental policy does not require the regulator to tax discriminate across domestic industries. This is a case of increasing policy relevance as governments continue to seek implementation of international environmental policy for multi-industry inputs such as $\mathrm{NO}_{x}, \mathrm{SO}_{2}$, and $\mathrm{CO}_{2}$. When a single polluting input is used to produce multiple export products, our policy recommendation is to allow for vertical contracts, to distress from export subsidization, and at the same time, to implement environmental regulation in the Pigouvian spirit.

Our findings also emphasize an unrecognized and potentially important connection between environmental policy, international trade, and antitrust legislation. If vertical contracts are not allowed under prevailing national (and international) antitrust laws, then the familiar strategic environmental trade policy results emerge once more. Future research on strategic environmental trade policy should focus, not just on domestic pollution control policies, but on other 
institutional features of governance, such as the enactment, enforcement, and adjudication of national and international antitrust laws, that place these activities outside the scope of private contract design.

\section{References}

[1] S. Barrett, Strategic environmental policy and international trade, J. Public Econ. 54 (1994) $325-338$.

[2] G. Bonanno, J. Vickers, Vertical separation, J. Ind. Econ. 36 (1988) 257-265.

[3] J. Brander, B. Spencer, Export subsidies and international market share rivalry, J. Int. Econ. 16 (1985) $227-242$.

[4] A.T. Coughlin, B. Wernerfelt, On credible delegation by oligopolists: a discussion of distribution channel management, Manage. Sci. 35 (1989) 226-239.

[5] K. Conrad, Taxes and subsidies for pollution-intensive industries as trade policy, J. Environ. Econ. Manage. 25 (1993) 121-135.

[6] J. Eaton, G.M. Grossman, Optimal trade and industrial policy under oligopoly, Quart. J. Econ. 101 (1986) 383-406.

[7] J. Friedman, Oligopoly Theory, Cambridge University Press, New York, 1983.

[8] S. Hamilton, K. Stiegert, Vertical coordination, antitrust law, and international trade, J. Law Econ. 43 (2000) $143-156$.

[9] S. Hamilton, K. Stiegert, An empirical test of the rent-shifting hypothesis: the case of state trading enterprises, J. Int. Econ. 58 (2002) 135-157.

[10] P.W. Kennedy, Equilibrium pollution taxes in open economies with imperfect competition, J. Environ. Econ. Manage. 27 (1994) 49-63.

[11] J.R. Markusen, International externalities and optimal tax structures, J. Int. Econ. 5 (1975) 15-29.

[12] R. Morgenstern, Environmental taxes: dead or alive? Resources for the Future Discussion Paper 96-03, 1996.

[13] N. Nannerup, Strategic environmental policy under incomplete information, Environ. Resource Econ. 11 (1998) $61-78$.

[14] OECD, Environmental taxes and green tax reform, OECD Council at Ministerial Level, C/MIN(97)12, 1997.

[15] G. Shaffer, Slotting allowances and resale price maintenance: a comparison of facilitating practices, RAND J. Econ. 22 (1991) 120-135.

[16] R. Simpson, R. Bradford, Taxing variable cost: environmental regulation as industrial policy, J. Environ. Econ. Manage. 30 (1996) 282-300.

[17] A. Ulph, Environmental policy and international trade when governments and producers act strategically, J. Environ. Econ. Manage. 30 (1996) 265-281.

[18] D. Ulph, Strategic innovation and strategic environmental policy, in: C. Carraro (Ed.), Trade, Innovation, Environment, Kluwer, Dordrecht, 1994, pp. 205-228.

[19] J. Vickers, Delegation and the theory of the firm, Econ. J. 95 (Suppl.) (1985) 138-147. 